\title{
Students' first experience with Objective Structured Clinical Examination in a pharmacy school in Indonesia
}

\author{
Susi Ari Kristina ${ }^{1 *}$, Nuvi Gustriawanto ${ }^{2}$, M. Rifqi Rokhman ${ }^{1}$, Hardika Aditama ${ }^{1}$, Ika Puspita Sari ${ }^{3}$ \\ ${ }^{1}$ Department of Pharmaceutics, Faculty of Pharmacy, Universitas Gadjah Mada, Yogyakarta, Indonesia. \\ ${ }^{2}$ Research Assistant of Department of Pharmaceutics, Faculty of Pharmacy, Universitas Gadjah Mada, Yogyakarta, Indonesia. \\ ${ }^{3}$ Department of Pharmacology and Clinical Pharmacy, Faculty of Pharmacy, Universitas Gadjah Mada, Yogyakarta, Indonesia.
}

\section{ARTICLE INFO \\ Article history: \\ Received on: 19/02/2018 \\ Accepted on: 15/05/2018 \\ Available online: 30/09/2018}

\section{Key words:}

objective standardized

clinical examination

(OSCE), pharmaceutical

care, pharmacy students,

assessment, Indonesia.

\begin{abstract}
Objectives: The study objective was to determine the effectiveness of the introduction of OSCE and pharmacy students perception regarding OSCE implementation. Methods: A 7-station OSCE was developed and implemented in the 2015-2016 academic year as part of compulsory pharmacy course. The case competencies examined include pharmaceutical skill practices covered clinical skills, compounding skills, and management skills incorporated into communication aspect. A questionnaire containing items on student perception and acceptance on OSCE implementation was administered after all students completed the OSCE. Results: About 224 and 198 students have completed the evaluation of the OSCE as part of their required courses. Class of 2016 performed better than 2015 counterpart in almost stations. The performance on the drug monitoring station across all classes was relatively poor (55\% and $69 \%$ passed). Students agreed that the OSCE scenario was relevant with real practice, a high degree of learning gained, and high fairness of assessment, consistency performance of simulated patients, yet the level of difficulty associated with performing tasks is very high, and the students felt that the 10 minutes allocated for completing each task was inadequate. Conclusion: Objective structured clinical examinations can be implemented routinely for assessment of students' clinical skills.
\end{abstract}

\section{INTRODUCTION}

Healthcare professionals are supposed to point good clinical skills to provide effective pharmaceutical care (Mitchell et al., 2012). Pharmacists are expected to implement patient care plans that require advance clinical, problem solving, and communication skills (Tindall et al., 1994; Boyce, 2017).

The Indonesian Pharmacists Association (IPA) provides curricular guidance on the knowledge, skills, and attitudes necessary for entry-level graduates called Indonesian Pharmacist Competencies. Domains of competencies focus on pharmaceutical basic knowledge used to evaluate scientific evidence literature, essentials skills for patient-centered practice, conduct patient education and health promotion, having leadership

\section{${ }^{*}$ Corresponding Author}

Susi Ari Kristina, Department of Pharmaceutics, Faculty of Pharmacy, Universitas Gadjah Mada, Yogyakarta, Indonesia.

E-mail:susiari_k@ugm.ac.id and management skills, and ability to perform professionally (Indonesian Pharmacists Association, 2016). Pharmacy schools should prepare students to pass licensure examination and provide merit clinical services to patients. Association of Indonesian Pharmacy Higher Education (AIPHE) encourages the development of critical thinking and problem-solving skills through activelearning strategies (Association of Indonesian Pharmacy Higher Education (AIPHE), 2013). It notes the use of clinical cases on pharmacy practice experience.

Objective Structured Clinical Examination (OSCE) was defined as a standardized examination of assessing student performance on clinical tasks (Zayyan, 2011). The examination consists of various stations at which students must complete specific clinical tasks, some situation in an interaction with simulated patients. The OSCE has become a standard method to assess performance across health professionals (Shirwaikar, 2015). In the US and Canada, OSCE is a component of entryto-practice licensing examinations for medical students (Sturpe, 2010; Vyas et al., 2013). 
In many pharmacy schools, this method is being widely used to evaluate the skills of pharmacy students. For example, an extensive study in the US indicated that $37 \%$ of pharmacy schools use the Objective Structured Clinical Examination (OSCE) (Sturpe, 2010). In fact that almost of pharmacy students work focusing on patient care, the most important part of the pharmacy curricula are clinical pharmacy internship (Hussain et al., 2017). Due to the importance of pharmacy internship in the education of pharmacy students, a standard method for evaluating pharmacy students' clinical skills is required (Kim et al., 2017).

The upcoming 2019 National Committee on Pharmacist Competency Examination set the standards to encourage pharmacy schools to implement the OSCE method for the competency assessment of entry-level pharmacists. In 2020, therefore, it is an obligation for all schools of pharmacy in Indonesia to move toward implementation of OSCE for summative assessment purposes (National Examination on Pharmacists Competencies Committee (NEPCC), 2017). In order to ensure the reliability of OSCE method, the national committee on OSCE developed the OSCE blueprint, provide training of standardized patients and examiners prior to the examination, and use of a validated method to establish passing grades (National Examination on Pharmacists Competencies Committee (NEPCC), 2017).

As compared to multiple-choice testing, OSCE has reported its reliability and validity (Kirton and Kravitz, 2011), covering a wide range like problem-solving, communication skills, decision-making, preparing medication and patient management abilities as a component of summative assessments (Hughes et al., 2013). Overall it has better psychometric properties than traditional methods (Setyonugroho et al., 2015).

As the use of OSCE grows within pharmacy education and little is known about how OSCEs are implemented within Indonesia pharmacy schools, the goals of this study were to evaluate pharmacy students' skills using the OSCE tool and to assess students' perception and acceptance about the OSCE.

\section{MATERIALS AND METHODS}

\section{Study design}

Pharmacy students enrolled in the academic year 2015 and 2016 were required to complete the OSCE as a onecredit compulsory course. The assessment using the OSCE was conducted at the end of the first semester of each class. The purpose of OSCE was to assess students' skills in pharmaceutical care competencies include clinical and administrative pharmacy skills. This study was part of OSCE pilot project held by Faculty of Pharmacy, Universitas Gadjah Mada, and proposed to be exit exam provided by pharmacy council in national level. A self-administered questionnaire survey to explore student perception and acceptance regarding the OSCE implementation was conducted after the completion of the OSCE.

\section{Setting}

The study was conducted in the Faculty of Pharmacy, Universitas Gadjah Mada, located in Yogyakarta province, Indonesia. The one-year professional degree has been received full accreditation status (entry-to-practice degree) in 2016 from the Indonesian Accreditation Agency for Higher Education in Health and, therefore, must be ready to implement educational initiatives in line with national standards. It implies that faculty will provide the OSCE assessment every student's year batch.

\section{OSCE implementation}

The OSCE was comprised of 7 stations consisting of pharmacy competencies tasks which must be performed by students. Cases of each station were developed from previous focus group between faculty members and practicing pharmacists with real practice combination. Case competencies examined include pharmaceutical skill practices covered clinical skills, compounding skills, and management skills incorporated into communication aspect. Prior to the OSCE implementation, simulated patients recruited from non-academic staffs were trained. The training encompassed role-playing for possible interactions with the student during the OSCE.

Each assessment was timed, and students circulated through each station. Each case composed of a 10-minute period with task either interaction with simulated patients or written form provided. Simulated patients were employed in interactive stations and written form was used in non-interactive stations. One trained examiner in pair evaluating student performance at the designated station using a standardized rubric. Three stations required students to interact with a simulated patient (SP), while the rest stations did not. Immediately after each encounter, these two examiners (faculty members) independently graded student performance using checklists. The provided checklists incorporated an analytical checklist for content and a four-point Likert global rating scale. OSCE assessment accounts 1-credit value to a student's grade but does not contribute to their professional degree completion requirement.

The OSCE was followed by an anonymous survey of all students to assess their perception and acceptance of the OSCE implementation. The questionnaire was adapted from a previously validated instrument used to evaluate a similar characteristic of students (Awaisu et al., 2007). Modifications were made to fit the study objectives. The instrument then was reviewed by senior faculty members and further adjusted for use in the study.

Ten set of questions were asked by means of a questionnaire to gather demographic data and main questions evaluating the OSCE stations in terms of real-life scenario, the difficulty of the tasks, perceived a degree of learning gained and needed, the time provided, and the overall acceptance of the OSCE. Responses were scaled on a 4-point Likert of strongly agree, agree, disagree, and strongly disagree. Students completed the survey immediately after finishing the OSCE. No disclosure of identity was needed on the questionnaire.

\section{Data analysis}

The data were analyzed using SPSS, version 12, (SPSS, Inc, Chicago, IL). Most of the data were analyzed using descriptive statistics to report student perception. Comparison of OSCE assessment results between classes was done using MannWhitney test. All values were considered significant if the p-value was less than 0.05 .

\section{RESULTS}

About 224 and 198 students completed the evaluation of 
the OSCE as part of their required courses during the year of study 2015 and 2016. Among them, 39 (9.24\%) was male students. The OSCE assessment was followed by a short, anonymous survey of all students to assess their perception and acceptance of the OSCE as an assessment tool. We compared overall performance and their perception between the class of 2015 and 2016.

We assessed students' performing skills at the 7 OSCE stations evaluating competences in minor illness, extemporaneous compounding, providing information regarding drug use to the patients, identifying drug-related problems, drug monitoring, drug distribution, and assessing their ability to counsel patients concerning special technique delivery devices (Table 1). Among students of class 2015 , most of them $(>75 \%)$ passed in stations of minor illness, extemporaneous compounding, providing information to patient, identifying DRP, but only $55 \%, 65 \%$, and $69 \%$ students passed through station drug monitoring, drug management, and use of drug with special technique respectively.

Table 1: Comparison of competency scores by pharmacy student' class.

\begin{tabular}{lccc}
\hline & \multicolumn{2}{c}{$\begin{array}{c}\text { Number of students passed, } \\
\text { N (\%) }\end{array}$} & \\
\cline { 2 - 3 } & $\begin{array}{c}\text { Class of 2015 (N } \\
\mathbf{2} \mathbf{2 2 4})\end{array}$ & $\begin{array}{c}\text { Class of 2016 (N) } \\
\mathbf{2 1 9 8})\end{array}$ & \\
\hline Stations & $189(84)$ & $169(85)$ & 0.18 \\
$\begin{array}{l}\text { Station 2. Extemporaneous } \\
\text { compounding }\end{array}$ & $176(78)$ & $160(81)$ & 0.078 \\
$\begin{array}{l}\text { Station 3. Providing information } \\
\text { to patient }\end{array}$ & $180(80)$ & $156(79)$ & 0.861 \\
$\begin{array}{l}\text { Station 4. Identifying Drug } \\
\text { Related Problems }\end{array}$ & $175(78)$ & $149(79)$ & 0.214 \\
$\begin{array}{l}\text { Station 5. Drug monitoring } \\
\text { Station 6. Drug distribution }\end{array}$ & $124(55)$ & $135(69)$ & $<0.001$ \\
$\begin{array}{l}\text { Station 7. Use of drug with } \\
\text { special technique }\end{array}$ & $146(65)$ & $147(74)$ & $<0.001$ \\
\hline
\end{tabular}

*passed means students received grade A or B.

Student class of 2016 performed better than 2015 counterpart in almost stations. Students performed better on the clinical portion of the drug monitoring, drug distribution, and use of the drug with a special technique, with a significant increase in a number of students passed $(69,74$, and $81 \%)$. This result was expected because a more advanced OSCE preparation was integrated into their curriculum. This also may because 2016 students had more and updated exposure to these clinical concepts and management aspect in the didactic lectures and simulation practice. Students demonstrated significant score progression in performance between 2015 and 2016.

The performance on the drug monitoring station across all classes was relatively poor (55\% and $69 \%$ passed). This particular station entailed the student to assess patient condition and to suggest clinical recommendation to the physician. Poor performance may potentially happen due to lack of knowledge comprehension on the topic. In addition, students were not adequately exposed and addressed to this type of problems. Because of these findings, SOAP method (Subjective, Objective, Assessment, and Plan) was added to the curriculum and is practiced in the pharmacy practice course in third-year students.

Evaluation of student perception and acceptance related to the OSCE were assessed after students completed their tasks in the OSCE. Students were asked to assess the relevancy of scenario developed with real practice, the degree of learning, the fairness of assessment, the consistency of simulated patient, the comparative difficulty associated with performing a task, time adequacy, and overall acceptance.

Table 2: Evaluation of student perception and acceptance of OSCE method.

\begin{tabular}{ccc}
\hline \multirow{2}{*}{ Perception and acceptance } & \multicolumn{2}{c}{ Mean (SD) $^{*}$} \\
\cline { 2 - 3 } & $\begin{array}{c}\text { Class of 2015 } \\
\mathbf{( N = \mathbf { 2 2 4 } )}\end{array}$ & $\begin{array}{c}\text { Class of 2016 } \\
\mathbf{( N = 1 9 8 )}\end{array}$ \\
\hline Relevancy of scenario with real practice & $3.56(0.78)$ & $3.43(0.86)$ \\
Degree of learning & $3.75(0.55)$ & $3.76(0.65)$ \\
Fairness of assessment & $3.43(0.61)$ & $3.45(0.55)$ \\
SP consistency & $3.21(0.81)$ & $3.23(0.54)$ \\
Level of difficulty & $3.89(0.34)$ & $3.78(0.91)$ \\
Time adequacy & $2.10(0.65)$ & $2.24(0.53)$ \\
Acceptance & $3.21(0.44)$ & $3.42(0.75)$ \\
\hline
\end{tabular}

*Mean score ranged from 1-4.

Students agreed that the OSCE scenario was relevant to their internship experiences of which was intended to reflect the real practice, perceived that OSCE was the methods that delivered high degree of learning gained, and high fairness of assessment, consistency performance of simulated patients, yet the level of difficulty associated with performing tasks is very high, and the students felt that the 10 minutes allocated for completing each task was inadequate. Overall, students satisfied and accepted the OSCE as an assessment tool. In comparison to the similar studies among pharmacy students, our results are consistent with respect to the OSCE providing a real-life practical experience (Awaisu et al., 2010; Allen et al., 2016).

\section{DISCUSSION}

This study provides important insight regarding the first experience in the OSCE implementation in Indonesia's pharmacy curricula. Our findings showed that 2016 students performed better than 2015 students. This finding was supposed because of their more progressive training skills and taking a laboratory coursework namely compounding and dispensing that provided the opportunity to role-play, practice, and feedback provided for their clinical and communication performance. A notable proportion of the students agreed that they gained a high degree of knowledge in all the stations of the OSCE. The OSCE allows students to incorporate clinical pharmacy knowledge, problemsolving skills, and communication skills into a single performance (Hastings et al., 2010).

These findings highlighted potential areas of advancement in students' knowledge and skills. Same lower performance is shown in students' problem-solving skills and therapeutic drug monitoring during experiential training. Efforts towards creating an expanded scope of knowledge and skills are needed to be initiated. Hence, the training on both aspects should be further improved. An OSCE, can be used to assess several components that are considered necessary for a successful pharmacist-patient interaction when providing pharmaceutical care including symptom knowledge, drug choices, potential side effects, communication and counseling skills, that together build 
the scope of competence of an individual student (Lin et al., 2011; Hastings et al., 2010).

To assure validity and consistency of the OSCE, representative clinical skills assessed with real-world practices should be tested. Consequently, use of a blueprint that defines competency domains (e.g., knowledge, skills, behaviors, professionalism) to guide OSCE station development along with group writing of OSCE cases with peer review has been recommended (Sobh et al., 2017). Maintaining station reliability through intensive simulated patient and examiners training, trial as well as pilot testing of stations, and the establishment of objective standard guidelines could also increase the OSCE consistency (Austin and Gregory, 2007).

Potential limitations of our study exist. Universitas Gadjah Mada has been interested in starting OSCE in order to measure students' performance in the OSCE form since 2015. However, we implemented the OSCE with limited cost and resources. The used classroom was not conducive enough to hold the OSCE because noises could still be heard although temporary partitions were placed. In our study, non-professional simulated patients were hired, moreover ensuring consistency of the patient's acting was difficult to be done due to limited training. While the OSCE is an effective assessment tool, it incurs higher resource usage than other assessment methods (Ameh et al., 2014; Troncon, 2004). This includes higher direct costs and faculty workload for case development and validation. In 2016, we allocated a preencounter OSCE preparation time about 1-2 minutes, in order to ease examination anxiety and potentially increase student score as they progressed between 2015 and 2016. Furthermore, adding the number of OSCE stations so that a reasonable scope of knowledge and skills tested has yet to be attained due to lack of resources.

Finally, trained examiners graded the interaction based on a rubric that consisted of communication and clinical skill checklists. We noted that the low consistency between examiners occurred although the same checklists were used to facilitate the grading by faculty members. It was noted in some studies that better reliability achieved by appointing healthcare professionals as examiners compared to faculty members, which could be considered for future testing (Seybert and Barton, 2007; Sobh et al., 2016).

\section{CONCLUSION}

This study provides student performance on clinical and communication skills using the OSCE. This study adds supporting evidence to OSCE as a type of clinical skills assessment for pharmacy students. The results of the OSCE can be used to evaluate curriculum and potentially to improve it. The findings from this study have important implications on students' preparedness for effective delivery of pharmaceutical care. In our expectation, the OSCE will become a national testing system used throughout the program to assess pharmacy students' competence in Indonesia.

\section{ACKNOWLEDGMENT}

Authors are thankful to all the faculty members who were involved in the OSCE and provided continued support.

\section{CONFLICT OF INTERESTS}

There are no conflicts of interest.

\section{REFERENCES}

Allen SJ, Waterfield J, Rivers P. An investigation of pharmacy student perception of competence-based learning using the individual Skills Evaluation and Development program, iSED ${ }^{\circledR}$. Pharm Educ. 2016; 16(1):72-80.

Ameh N, Abdul MA, Adesiyun GA, et al. Objective structured clinical examination vs traditional clinical examination: An evaluation of students' perception and preference in a Nigerian medical school. Niger Med J. 2014; 55(4):310-313.

Association of Indonesian Pharmacy Higher Education (AIPHE). 2013. Standard of Curricula for Indonesian Pharmacy Schools. Jakarta: AIPHE.

Austin Z, Gregory MLS. Evaluating the Accuracy of Pharmacy Students' Self-Assessment Skills. Am J Pharm Educ. 2007; 71(5): Article 89.

Awaisu A, Abd Rahman NS, Mohamed MHN, et al. Malaysian Pharmacy Students' Assessment of an Objective Structured Clinical Examination (OSCE). Am J Pharm Educ. 2010; 74(2): Article 34.

Awaisu A, Mohamed MHN, Al-Efa QAM. Perception of Pharmacy Students in Malaysia on the Use of Objective Structured Clinical Examinations to Evaluate Competence. Am J Pharm Educ. 2007; 71(6): Article 118

Boyce EG. The pharmacists' patient care process and more. Am J Pharm Educ. 2017; 81(4):62.

Hastings JK, Schwanda KF, Pace AC, et al. An Objective Standardized Clinical Examination (OSCE) in an Advanced Nonprescription Medicines Course. Am J Pharm Educ. 2010; 74(6): Article 98.

Hughes F, Barry J, Belaid L, et al. Development of an Objective Structured Clinical Examination (OSCE) to assess formulation and extemporaneous dispensing skills in MPharm undergraduates. Pharm Educ. 2013; 13(3):7-14.

Hussain A, Malik M, Abdullah S. Review of evolving trends in clinical pharmacy curriculum around the globe. Am J Pharm Sci. 2017; 5(2):1-7.

Indonesian Pharmacists Association. 2016. Indonesian Pharmacists Competencies Standard. Jakarta: Indonesian Pharmacists Association.

Kim JH, Lee JY, Lee YS, et al. Attitudes to proposed assessment of pharmacy skills in Korean pharmacist licensure examination. J Educ Eval Health Prof. 2017; 14(6)

Kirton SB, Kravitz L. Objective Structured Clinical Examinations (OSCEs) Compared With Traditional Assessment Methods. Am J Pharm Educ. 2011; 75(6): Article 111.

Lin K, Travlos DV, Wadelin JW, et al. Simulation and introductory pharmacy practice experiences. Am J Pharm Educ. 2011; 75(10):209.

Mitchell P, Wynia M, Golden R, et al. 2012. Core Principles and Values of Effective Team-Based Health Care Discussion Paper. Washington DC: Institute of Medicine.

National Examination on Pharmacists Competencies Committee (NEPCC). 2017. Blueprint Ujian Kompetensi Apoteker Indonesia. Jakarta: NEPCC.

Setyonugroho W, Kennedy KM, Kropmans TJ. Reliability and validity of OSCE checklists used to assess the communication skills of undergraduate medical students: A systematic review. Patient Educ Couns. 2015; 98(12):1482-1491.

Seybert AL, Barton CM. Simulation-Based Learning to Teach Blood Pressure Assessment to Doctor of Pharmacy Students. Am J Pharm Educ. 2007; 71(3): Article 48.

Shirwaikar A. Objective structured clinical examination (OSCE) in pharmacy education - a trend. Pharm Pract. 2015; 13(4):627.

Sobh A, Pawluk SA, Izham M, et al. Qualitative evaluation of a cumulative exit-from-degree objective structured clinical examination (OSCE) in a Gulf context. Pharm Educ. 2017; 17(1):73-80.

Sobh A, Wilby KJ, Izham M, et al. Evaluation of a cummulative 
performance-based assessment for pharmacy students in Qatar. Qatar Foundation Annual Research Conference Proceedings, 21 Mar 2016; Suppl 1.

Sturpe DA. Objective Structured Clinical Examinations in Doctor of Pharmacy Programs in the United States. Am J Pharm Educ. 2010; 73(4): Article 148.

Tindall WN, Beardsley RS, Kimberlin CL. 1994. Communication Skills in Pharmacy Practice: a Practical Guide for Students and Practitioners. Baltimore: Lea \& Febiger.

Troncon LEA. Clinical skills assessment: limitations to the introduction of an "OSCE" (Objective Structured Clinical Examination) in a traditional Brazilian medical school. Sao Paulo Med J. 2004; 122(1): 12-7. Vyas D, Bray BS, Wilson MN. Use of simulation-based teaching methodologies in US colleges and schools of pharmacy. Am J Pharm Educ. 2013; 77(3):53.

Zayyan M. Objective Structured Clinical Examination: The assessment of choice. Oman Med J. 2011; 26(4):219-222.

How to cite this article:

Kristina SA, Gustriawanto N, Rokhman MR, Aditama H, Sari

IP. Students' first experience with Objective Structured Clinical

Examination in a pharmacy school in Indonesia. J App Pharm

Sci, 2018; 8(09): 102-106. 